\title{
Erratum to: Comparison of the Phase III Clinical Trial Designs of Novel Oral Anticoagulants Versus Warfarin for the Treatment of Nonvalvular Atrial Fibrillation: Implications for Clinical Practice
}

\author{
Carlos J. Gonzalez-Quesada $\cdot$ Robert P. Giugliano
}

Published online: 29 April 2014

(C) Springer International Publishing Switzerland 2014

Erratum to: Am J Cardiovasc Drugs (2014) 14:111-127 DOI 10.1007/s40256-013-0062-z

Page 115, Fig. 1, Parts $\mathrm{A}$ and $\mathrm{C}$ which previously showed:

the dosing schedule for dabigatran as $150 \mathrm{mg}$ QD and $110 \mathrm{mg}$ QD and for apixaban as $5 \mathrm{mg}$ QD, respectively should show:

the dosing schedule for dabigatran as $150 \mathrm{mg}$ BID and $110 \mathrm{mg}$ BID and for apixaban as $5 \mathrm{mg}$ BID, respectively

Page 116, Table 2, column 2 (RE-LY), the aspirin dose which previously read as:

not specified

should read as:

$>100 \mathrm{mg} /$ day excluded
Page 121-122, Table 4, column 1, the last three rows which previously read as:

(annualized \%)

should read as:

(\%)

The online version of the original article can be found under doi:10. 1007/s40256-013-0062-z.

C. J. Gonzalez-Quesada

Department of Medicine, Brigham and Women's Hospital,

75 Francis St., Phyllis Jen Center for Primary Care (Suite A),

Boston, MA 02115, USA

R. P. Giugliano $(\square)$

TIMI Study Group, Cardiovascular Division, Brigham and

Women's Hospital, 350 Longwood Ave., 1st Floor Offices,

Boston, MA 02115, USA

e-mail: rgiugliano@partners.org 